\title{
A Comparative Study of Classic Laryngeal Mask Airway And Proseal Laryngeal Mask Airway in Patients Undergoing Different Surgical Procedures Under General Anesthesia.
}

\author{
Dr. Ranjeet Rana De ${ }^{1}$, Dr. Saurav Shekhar ${ }^{2}$, Dr. D G Pathak ${ }^{3}$, \\ Dr. Harshwardhan ${ }^{4}$, Dr. Shashank Dhiraj ${ }^{5}$ \\ ${ }^{1,2,4,5}$ Department Of Anesthesia And Critical Care, Indira Gandhi Institute Of Medical Sciences, India \\ ${ }^{3}$ Department Of Anesthesia And Critical Care, Gauhati Medical College And Hospital, India
}

\begin{abstract}
Introduction: Difficult airway is a nightmare situation for anesthesiologists and scenario has changed with introduction of LMA. Here, we intend to compare CLMA and PLMA in routine surgical procedures under general anesthesia.

Methodology: 60 patients were randomly allocated in 2 groups. Numbers of attempts and time taken for successful placement to achieve effective ventilation were recorded. Haemodynamic parameters, quality of ventilation (in terms of audible leak, chest movement, tidal volume loss, requirement of manipulation) and complications were recorded.

Results- First attempt insertion success rate were higher for the CLMA but after three attempts, success rate was same (93.3\%). Duration of significantly raised heart rate and blood pressure were longer in CLMA group than in PLMA group. By considering the leak, chest movement, tidal volume loss, manipulation required, $\mathrm{spo}_{2}$ and $\mathrm{EtCO}_{2}$, ventilation was adequate in $94 \%$ of patients in PLMA group and in $70 \%$ of patients in CLMA group. Sore throat was most common postoperative morbidity in both groups.

Conclusion: After consideration of satisfactory first attempt insertion success rate, ease of OGT placement, easy diagnosis of misplacement, less haemodynamic changes, better quality of ventilation and less postoperative morbidity, we conclude that proseal LMA is a better option for airway management.
\end{abstract}

Keywords: Classic laryngeal mask airway, Proseal laryngeal mask airway, Seal pressure, Difficult airway

\section{Introduction}

Safe airway management still remains a challenge for the anesthesiologist. Direct laryngoscopy and endotracheal intubation is considered to be the safest way to safeguard the airway but life threatening situation like 'cannot intubate, cannot ventilate' situation may occur to anyone, anywhere and anytime. LMA has been introduced since 1981 and has changed the scenario from 'cannot intubate, cannot ventilate' to ' cannot intubate ,can ventilate ${ }^{1}$. It is aptly termed "Supraglottic" airway device as it is positioned in hypopharynx above the vocal cords and requires no direct visualization of the glottic opening for successful placement and thus helpful in situations of difficult intubation. Disadvantages of classical LMA over the tracheal tube are lower seal pressure ${ }^{2}$, a higher frequency of gastric insufflation and also increased risk of aspiration of gastric contents which led to the development of modified designs of LMA to enable separation of the gastrointestinal and respiratory tracts, improve the airway seal, enable controlled ventilation and diagnose mask misplacement ${ }^{3}$.Proseal laryngeal mask airway (PLMA), designed by Dr. Archie Brain, has several design modifications like larger and softer wedge shaped cuff to adapt the shape of the pharynx and deeper PLMA bowl, contribute to the improved airway seal of the PLMA ${ }^{4,5,6,7,8}$. Ability to pass orogastric tube through PLMA allowed rapid diagnosis of mask misplacement together with ability of gastric emptying.

\section{Materials And Method}

After institutional ethical committee clearance and written informed consent, this prospective randomized clinical study was done in 60 patients of age group 18-50 years, weighing 30-50 kgs, ASA status I \& II and with interdental gap $>2.5 \mathrm{~cm}$. Those excluded were of ASA grade $>2$, emergency cases, anticipated difficult airway, full stomach and inter dental gap $<2.5 \mathrm{~cm}$. Pre-anesthetic checkup was done in evening before surgery. On the day of operation, patients were shifted to the operation theatre and standard routine monitors were attached like continuous electrocardiography, noninvasive blood pressure, and oxygen saturation with pulse oximetry and baseline values were recorded. An 18G intravenous access established and lactated Ringer's solution was started. Patients were randomly allocated into two groups- Group $1(\mathrm{n}=30)$ received classic Laryngeal mask airway (CLMA group) while Group $2(\mathrm{n}=30)$ received Proseal Laryngeal mask airway ( PLMA group). 
All patients received premedication of injection Glycopyrrolate $0.2 \mathrm{mg}$ IV, injection midazolam $25 \mathrm{mcg} / \mathrm{kg}$ and injection fentanyl $2 \mathrm{mcg} / \mathrm{kg} 10$ minutes prior to induction. Patients were preoxygenated for 3 minutes and then induced with intravenous propofol $2 \mathrm{mg} / \mathrm{kg}$ followed by inj. Vecuronium bromide $0.1 \mathrm{mg} / \mathrm{kg}$ for neuromuscular blockade. Then patients were ventilated with 100\% oxygen for 3 minutes via facemask using close circle system at 14-16 breaths per minute. Both devices were introduced in supine position with a standardized manner. PLMA was introduced by using digital method.In both groups, following successful insertion of the device, patients were maintained with $66 \% \mathrm{~N} 2 \mathrm{O}$ in oxygen and Halothane with closed circle system at 14-16 breaths per minute and tidal volume $10 \mathrm{ml} / \mathrm{kg}$. Heart rate, noninvasive blood pressure, $\mathrm{Spo}_{2}$, $\mathrm{EtCO}_{2}$ and any complication if found were recorded intraoperatively.

Parameter recorded for study:-Quality of insertion was assessed in terms of number of attempts and time taken for successful placement to achieve effective ventilation. A maximum of three attempts were allowed and failed attempt was declared after 3 unsuccessful attempts and in such situation oral endotracheal intubation were done. Time taken for successful placement was calculated as that from the removal of the facemask used for preoxygenation to placement of device and achieving effective ventilation. Ease of passage of orogastric tube was assessed with number of attempts needed for correct placement of the orogastric tube.

Haemodynamic parameters like Pulse rate and systolic and diastolic blood pressure were recorded immediately prior to induction (control) and subsequently at $1 \mathrm{~min}, 3 \mathrm{~min}, 5 \mathrm{~min}, 7 \mathrm{~min}$ and $10 \mathrm{~min}$ following successful device placement.

Ventilation was considered adequate if there were no leak and preset tidal volume of $10 \mathrm{ml} / \mathrm{kg}$ with $33 \%$ of oxygen achieves good chest movement, normal square shaped $\mathrm{EtCO}_{2}$ graph and $\mathrm{spo} 2>98 \%$ \& there were no tidal volume loss more than $30 \%$. Tidal volume loss was detected by inspiratory-expiratory volume on the ventilator display screen. Manipulation like increase in cuff volume for achievement of effective seal pressure was also recorded. Any intraoperative and postoperative complications like sore throat, hoarseness or dysphagia were recorded. Residual neuromuscular block was reversed at appropriate time as judged clinically after completion of surgery with inj. Neostigmine $(0.05 \mathrm{mg} / \mathrm{kg})$ and inj Glycopyrrolate $(0.01 \mathrm{mg} / \mathrm{kg} \mathrm{wt})$ intravenously.Statistical analysis was done with student's' test and wherever normal distribution was not found, appropriate non-parametric tests were performed on InStat3 software. Power analysis was also done for the exact difference between the two groups for all the variables

\section{Results And Observation}

100 patients were taken according to the study protocol out of which sixty patients were selected which met all the inclusion criteria and divided into two groups of thirty each. Demographic profile like gender distribution, ASA physical status and mallampatti grading of both group were found statistically similar (TABLE 1) It was observed that in Group I , CLMA could be successfully placed in first attempt in $83.3 \%$ patients while in Group II first attempt PLMA placement was possible only in $73.3 \%$. However this difference was statistically insignificant $(\mathrm{p}=0.5321)$. It was observed that the second attempt success rate was $6.67 \%$ in Group I (2 Patients) while there were requirement of second attempt in 16.67\%(5 patients) of patients of PLMA group. It was noted that $3^{\text {rd }}$ attempt was necessary for device insertion in $3.3 \%$ in both groups. Failed insertion was recorded in $6.67 \%$ ( 2 patients) in both groups. (TABLE 2)

It was observed that the mean time to place the airway device in CLMA group was 20.78 seconds while 21.64 seconds in PLMA group but the difference was statistically insignificant. (TABLE 2) It was found that the orogastric tube could be successfully placed in the $1^{\text {st }}$ attempt in $60 \%$ patients in group I and in $83.3 \%$ patients in group II. (TABLE 2)

On comparison of quality of ventilation in terms of audible air leak over mouth after achieving a cuff pressure of $60 \mathrm{~cm}$ of $\mathrm{H}_{2} \mathrm{O}$ with recommended volume of air, it was found that the audible leak in CLMA group was significantly higher $(30 \%$; 9 patients) than the PLMA group $(6.7 \% ; 2$ patients) $(\mathrm{p}=0.0419)$. Qualities of ventilation in terms of chest movement were found good in most of the cases in both the groups (96\% in PLMA group versus $90 \%$ in CLMA group) which was statistically insignificant.. Tidal volume loss as found insignificantly higher in CLMA group than that in PLMA group (16\% and $4 \%$ respectively). After considering all the parameter of ventilation in our study, it was found that ventilation was adequate in approximately $94 \%$ of the patients in PLMA group and only in 70\% in CLMA group which was statistically significant. (TABLE 3)

There was extremely significant increase in the heart rate \& blood pressure compared to the preinsertion values, immediately after placement of the device in both groups. This increase in heart rate \& blood pressure persisted for a period of 1 minute in PLMA group while in CLMA group this increase continued for 3 min after which the heart rate \& blood pressure returned to near pre-insertion values in both the groups. (GRAPH 1,2 \& 3) Oxygen saturation was well maintained throughout the procedure in both groups. EtCO $\mathrm{Eas}_{2}$ well maintained throughout the procedure in both groups but statistically significant changes from the baseline in group CLMA were noted at 1min, 10mins and 45 mins and in group PLMA from 5 to 45 min but it were 
clinically acceptable. On comparison between two groups significant changes were noted at 20 min which were clinically acceptable.(GRAPH 4 \& 5)

Sore throat was found in 5 cases $(16.6 \%)$ in CLMA group and $2(6.6 \%)$ cases in PLMA group. Gastric insufflation was noted in 4 cases, regurgitation in 2 cases and Hoarseness in 2 cases of CLMA group while in PLMA no such problems were seen.

\section{Discussion}

Supraglottic airway devices have become an essential in airway management, filling a niche between the face mask and tracheal tube in terms of both anatomical position and degree of invasiveness. The introduction of Proseal LMA, reduces the risk of aspiration \& gastric insufflation, improves the airway seal \& enables controlled ventilation at higher seal pressure.First attempt insertion success rate was higher for the CLMA (CLMA 83\%; PLMA73.3\%) but after three attempts, success rate was same (93.3\%) for both the groups. The mean time required for PLMA insertion was more than with CLMA insertion ( $>0.05)$. Lower first attempt success rate and slightly more time requirement in PLMA placement may be caused by the larger, deeper, softer bowl and the non-linear leading edge formed by the drainage tube. Failure in CLMA placement in 2 patients can be explained by the soft tissue resistance due to falling back of the tongue against the posterior pharyngeal wall while in PLMA group was most probably due to folding of mask tip as we were also unable to insert the orogastric tube in them. Therefore inability to pass OGT can be used in diagnosis of misplacement of PLMA. Brimacombe et al( 2002) also found first attempt success rate higher(LMA91\%,PLMA82\%) for the LMA group but after three attempts, success rate were similar(LMA 100\%,PLMA 98\%) in both groups ${ }^{4}$.

In the present study first attempt insertion of OGT were higher in PLMA group (83.3\%) in comparison to CLMA group (60\%). Overall success of OGT placement was $83.3 \%$ in CLMA while in PLMA group it was 93.3\%.Brimacombe et al, Brimacombe and keller, N.R.Evans et al, Cook TM et al ${ }^{4,6,7,8}$ also found significantly higher first attempt and overall success rate in PLMA group. Brimacombe and keller(2002) also stated that higher success rate for OGT passage (upto 100\%) are reported when efforts are made to eliminate folding of the mask tip.In this present study we observed that there was a significant rise in the Heart rate(HR),systolic blood pressure(SBP) and diastolic blood pressure (DBP) in both the groups following insertion of the respective devices which persisted longer in CLMA group. This haemodynamic changes can be explained by the fact that the larger, softer wedge shaped PLMA cuff adapt the shape of the pharynx better and there was less requirement of manipulation(like increase in cuff pressure) for effective seal.

Braun $\mathrm{U}$ et $\mathrm{al}^{9}$ observed that hemodynamic responses after insertion of PLMA were minimal and were similar to those of the classic laryngeal mask airway. Russo, Sebastian G et al observed the increase in heart rate by 9.3 \pm 2.3 after insertion of PLMA, which was significantly lower than the ETT group.We observed that despite of a steady maintenance of spo2 $>98 \%$ in some cases, there were leak which was detected by audible sound over the mouth by stethoscope. In the CLMA group leak was detected in 30\% (9) of patients, which was statistically significant than the PLMA group $(6.67 \% ; 2$ patients) ( $\mathrm{p}=0.0419$, Fisher's exact test). In all these cases there was requirement of manipulation along with an increase in the cuff volume.

ETCO2 and SPO2 remained satisfactory in both groups and were of no significance clinically. By considering all these parameters mentioned above like tidal volume loss, audible leak and good chest movement, ventilation was considered adequate in $94 \%$ of patients in PLMA group and $70 \%$ of patients in CLMA group, which was statistically significant $(\mathrm{p}<0.0419$ Fisher's exact test).

Brain AIJ et $\mathrm{al}^{3}$ compared PLMA with CLMA in 30 adult female patients and their observation were similar to our study that, proseal LMA gives twice the seal pressure than classic LMA ( $<<0.0001)$. Lu et $\mathrm{al}^{10}$ compared PLMA with LMA in 80 patients undergoing laparoscopic cholecystectomy \& concluded that PLMA is more effective ventilator device than the classic LMA. Although we did not included laparoscopic surgeries in our study but the findings were similar. Micaglio $\mathrm{M}$ et al ${ }^{13}$ compared proseal and classic laryngeal mask airway in neonates and infants and also observed that seal pressure was significantly higher for PLMA..There were 4 cases (13.3\%) of gastric insufflations and 2 cases $(6.6 \%)$ of regurgitation in the classic LMA group while no such incidence occurred in PLMA group. Our findings coincide with findings of Lettore F et $\mathrm{al}^{11}$ and Asai $\mathrm{T}$ et $\mathrm{al}^{12}$. They found gastric insufflations in $19 \%$ and $13.3 \%$ of cases respectively in CLMA group.

In the present study, sore throat was the most common postoperative morbidity recorded in both groups. However, the incidence of sore throat in classic LMA was more than that of PLMA group (16.6\% and $6.7 \%$ respectively). The incidence of hoarseness in this study was also more in Classic LMA group than the PLMA group $(6.7 \%$ and $0 \%$ respectively). The lower incidence of sore throat and hoarseness in PLMA group were probably due to lower intracuff pressure when using recommended intracuff air volume. 
V. Tables And Graphs

\begin{tabular}{|c|c|c|c|}
\hline & CLMA & PLMA & P value \\
\hline \multicolumn{3}{|c|}{ Demographic profile: } \\
\hline $\begin{array}{c}\text { Mean Age } \\
\text { (Years } \pm \text { SD) }\end{array}$ & $35.7 \pm 9.3$ & $36.26 \pm 8.5$ & $\mathrm{p}>0.05$ \\
\hline $\begin{array}{c}\text { Sex : Male } \\
\text { Female }\end{array}$ & 6 & 7 & $\mathrm{p}>0.05$ \\
\hline $\begin{array}{c}\text { Mean Weight } \\
\text { (kgs } \pm \text { SD) }\end{array}$ & $44.97 \pm 4.1$ & $44.06 \pm 5.14$ & $\mathrm{p}>0.05$ \\
\hline $\begin{array}{c}\text { ASA : Grade 1 } \\
\text { Grade 2 }\end{array}$ & 20 & 22 & $\mathrm{p}>0.05$ \\
\hline Mallampatti grade: & 10 & 8 & $\mathrm{p}>0.05$ \\
Class 1 & 16 & 18 & \\
Class 2 & 14 & 12 & \\
\hline
\end{tabular}

Table 1. Demographic profile

\begin{tabular}{|c|c|c|}
\hline & CLMA & PLMA \\
\hline \multicolumn{3}{|l|}{ Quality of insertion: } \\
\hline Attempts needed for successful placement of LMA: & & \\
\hline $1^{\text {st }}$ attempt & $25(83.3 \%)$ & $22(73.3 \%)$ \\
\hline $\begin{array}{l}2^{\text {rd }} \text { attempt } \\
3^{\text {rdtempt }}\end{array}$ & $1(3.3 \%)$ & $1(3.3 \%)$ \\
\hline Failed & $2(6.67 \%)$ & $2(6.67 \%)$ \\
\hline Time taken for successful insertion ( mean seconds \pm SD) & $20.78 \pm 3.19$ & $21.64 \pm 3.14$ \\
\hline Number of attempts for successful orogastric tube placement & $18(60 \%)$ & $25(833 \%)$ \\
\hline $2^{\text {nd }}$ attempt & $5(16.67 \%)$ & $\begin{array}{l}25(83.3 \%) \\
3(10 \%)\end{array}$ \\
\hline $3^{\text {rd }}$ attempt & $3(10 \%)$ & 0 \\
\hline Failed & $4(13.33 \%)$ & $2(6.67 \%)$ \\
\hline
\end{tabular}

Table 2. Quality of insertion of LMA \& Orogastric tube

\begin{tabular}{|c|c|c|c|}
\hline & CLMA & PLMA & $\begin{array}{c}\text { P value } \\
\text { (fischer exact test) }\end{array}$ \\
\hline \multicolumn{3}{|c|}{ Quality of ventilation } \\
\hline $\begin{array}{c}\text { Audible leak present (no. of patients) } \\
\text { patients) }\end{array}$ & $9(30 \%)$ & $2(6.67 \%)$ & $\mathrm{p}=0.0419$ \\
\hline $\begin{array}{c}\text { Inadequate chest movement (no. of } \\
\text { Tidal volume loss more than 30\% (no. of } \\
\text { patients) }\end{array}$ & $3(10 \%)$ & $1(3.3 \%)$ & $\mathrm{p}=0.612$ \\
\hline $\begin{array}{c}\text { Therefore; } \\
\text { Adequate quality of ventilation } \\
\text { Inadequate quality of ventilation(no. of } \\
\text { patients) }\end{array}$ & $\begin{array}{c}21(70 \%) \\
9(30 \%)\end{array}$ & $\begin{array}{c}28(93.4 \%) \\
2(6.67 \%)\end{array}$ & $\mathrm{p}=0.194$ \\
\hline
\end{tabular}

Table 3. Quality of ventilation

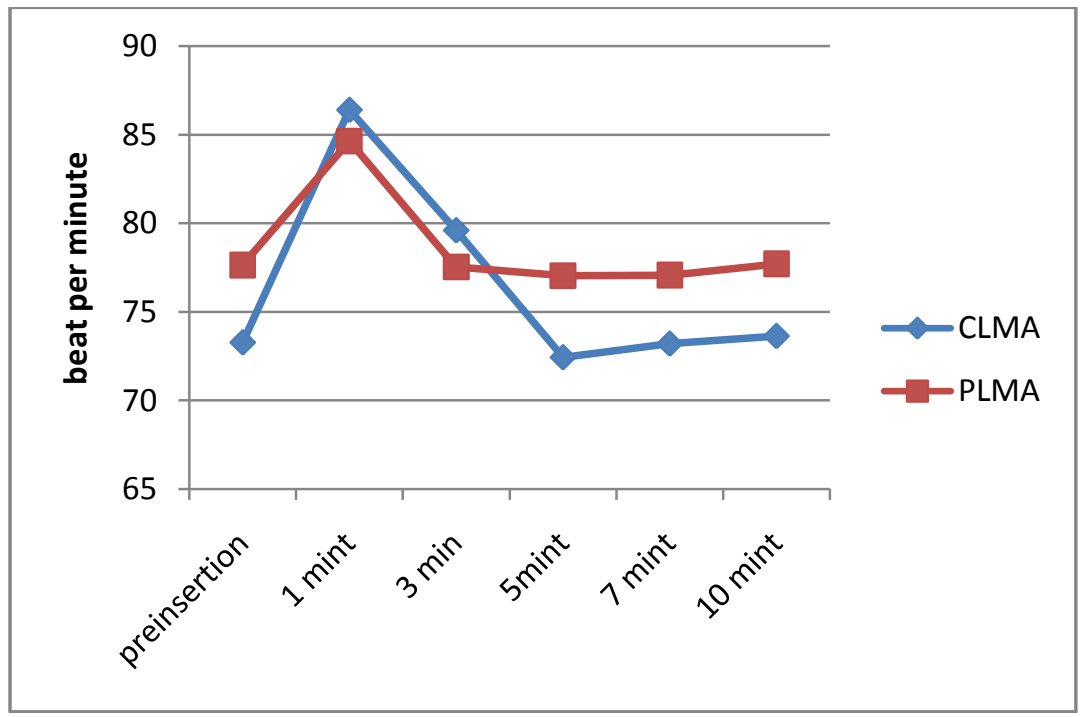

Graph 1- Heart rate variation 


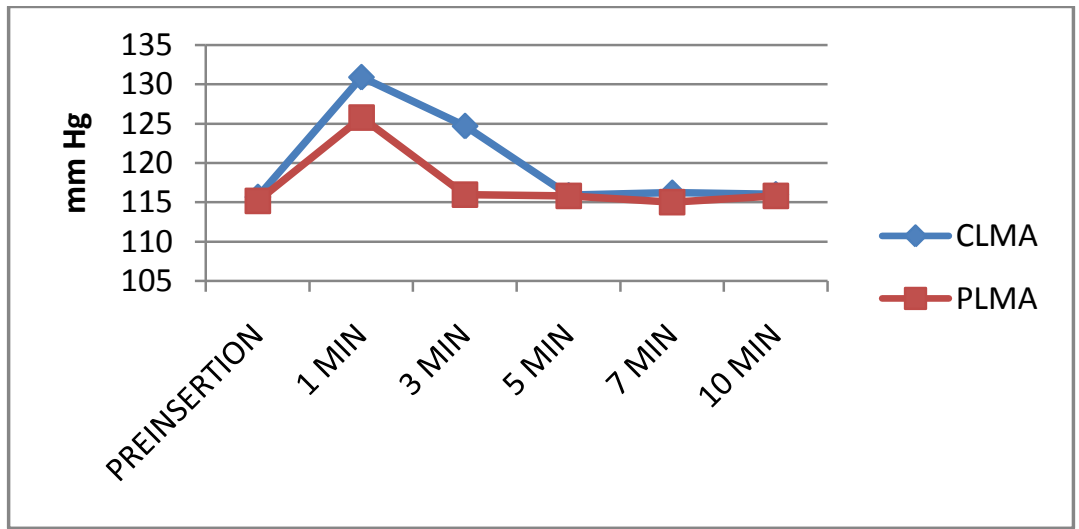

Graph 2- Mean systolic blood pressure

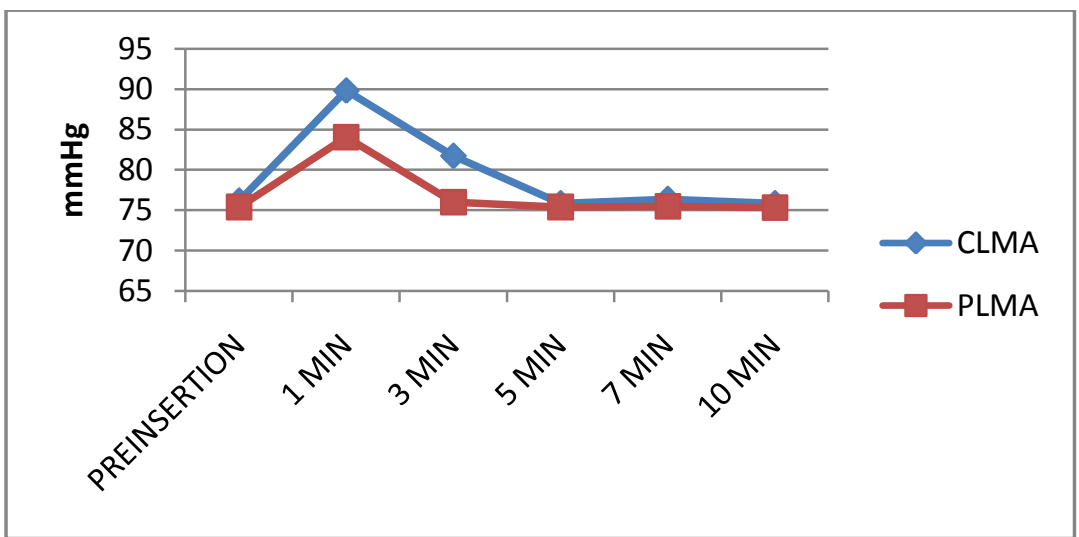

Graph 3- Mean diastolic blood pressure

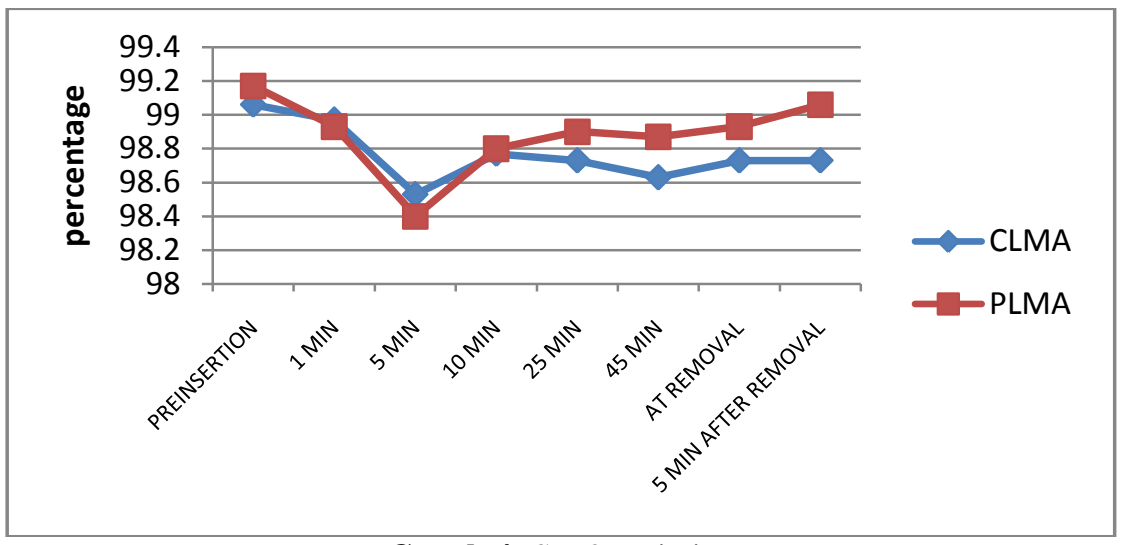

Graph 4- Spo2 variation

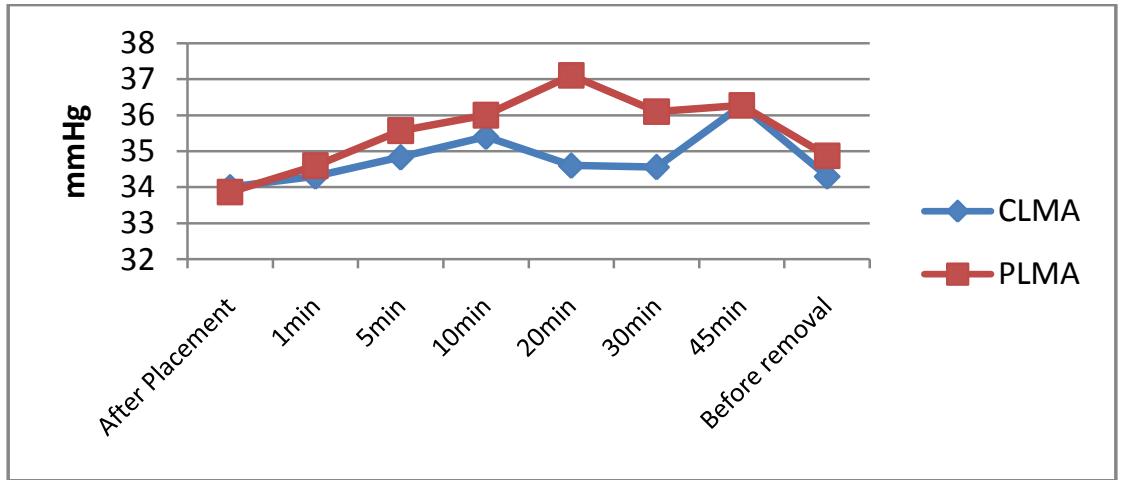

Graph 5- Etco2 variation 


\section{Conclusion}

After consideration of satisfactory first attempt insertion success rate, ease of OGT placement, easy diagnosis of misplacement, less haemodynamic changes, better quality of ventilation and less postoperative morbidity, we conclude that proseal LMA is a better option for airway management in experienced hands.

\section{References}

[1]. Brain AIJ .The Laryngeal Mask Airway-a new concept in airway management. Br J Anaesth 1983;55:801-804

[2]. Brain AIJ. Pressure in laryngeal mask airway cuffs.Anaesthesia 1996;51:603.

[3]. Brain AIJ, Verghese C, Strube PJ. The LMA "ProSeal"-a laryngeal mask with an esophageal vent. Br J Anaesth 2000;84:650-

[4]. Brimacombe J, Keller C. The ProSeal laryngeal mask airway. AnesthClin N Amer 2002;20:871-891.

[5]. Brimacombe J, Keller C. Aspiration of Geastric contents during use of a ProSeal TM laryngeal mask airway. AnesthAnalg, 2003;97:1192-4

[6]. Brimacombe J, Keller C, Fullekrug B, Agro F, Rosenblatt W, Dierdorf SF, Garcia de Lucas E, Capdevilla x, Brimacombe N.A multicentric study comparing the Proseal and classic laryngeal mask airways in anesthetized,nonparalyzed patients. Anesthesiology 2002;96:28

[7]. Cook TM, Lee G, Nolan JP. The ProSealTM laryngeal mask airway: a review of the literature. Can J Anesth 2005;52:739-760.

[8]. Evans NR, Gardner SV, James MFM. ProSeal laryngeal mask protects against aspiration of fluids in the pharynx. Br J Anaesth 2002;88:584-7.

[9]. Braun U, ZerbstM,Fullekberg B et al. A comparison of the Proseal laryngeal mask to the standard laryngeal mask on anesthetized,nonrelaxedpatients.Anesthesiol Intensity Med.2002;37:727-33

[10]. Lu PP, Brimacombe J, Yang C, Shyr M. ProSeal versus the Classic LMA for positive pressure ventilation during laparoscopic cholecystectomy. Br J Anaesth 2002;88:824-7.

[11]. Lettoree F et al. Assessment of LMA malpositioning by fibreoptic bronchoscopy and its influence on gastric insufflations and oropharyngeal air leakage. AnesthAnalg 1998;80(4):867-71

[12]. Asai T, Kawashima A, Hidaka I et al. The laryngeal tube compared with the Laryngeal Mask Airway insertion, gas leak pressure and gastric insufflations. Br J Anaesth 2002 Nov; 89(5):729-32

[13]. Micaglio M,Bonato R,De Nardin M, Parotto M, Trevisanuto D, Zanardo V,Doglioni N, Ori C. Prospective ,randomized comparison of proseal and classic laryngeal mask airways in anaesthetized neonates and infants. Br. J. Anaesth. (2009) 103 (2):263267 